\title{
Prevalence of human papillomavirus and Epstein-Barr virus DNA in penile cancer cases from Brazil
}

\author{
Larissa Alves Afonso', Natalia Moyses', Gilda Alves², Antônio Augusto Ornellas ${ }^{3}$, \\ Mauro Romero Leal Passos ${ }^{1}$, Ledy do Horto dos Santos Oliveira1, Silvia Maria Baeta Cavalcanti ${ }^{1 /+}$
}

1Departamento de Microbiologia e Parasitologia, Instituto Biomédico, Universidade Federal Fluminense, Rua Ernani Melo 101 Lab. 319 , 24210-130 Niterói, RJ, Brasil 'Laboratório de Genética Aplicada ${ }^{3}$ Serviço de Urologia, Instituto Nacional de Câncer, Rio de Janeiro, RJ, Brasil

Penile cancer is a potentially mutilating disease. Although its occurrence is relatively rare worldwide, penile cancer rates can be high in developing countries. A few studies have been conducted on the involvement of human papillomavirus (HPV) in penile carcinoma, which have found HPV present in 30-70\% of penile malignant lesions, with a higher prevalence of HPV 16 and 18. It has been assumed that cofactors, such as Epstein-Barr virus (EBV) infections, may play a role in the progression of penile neoplasia. The aim of this study was to determine HPV and EBV prevalence in 135 penile malignant lesions from Brazilian men through the use of MY09/11 polymerase chain reaction (PCR), type-specific PCR and restriction fragment length polymorphism analysis. HPV prevalence among the men tested was $60.7 \%$. Of the men who tested positive, 27 presented with HPV 16 (29.7\%), five with HPV 18 (5.5\%), 21 with HPV 45 (23.1\%) and nine with HPV 6 (9.9\%). Seven mixed infections were detected (9.2\%), while 11 cases remained untyped (13.4\%). Regarding EBV positivity, 46.7\% of the samples contained EBV DNA with EBV-1 as the most prevalent type (74.6\%). More than $23 \%$ of the men were co-infected with both HPV and EBV, while $35 \%$ presented exclusively with HPV DNA and $20 \%$ presented only with EBV DNA. Penile carcinoma aetiology has not been fully elucidated and the role of HPV and EBV infections individually or synergistically is still controversial. Hence, more studies are needed to determine their possible role in carcinogenesis.

Key words: HPV - EBV - PCR - penile cancer

Penile cancer is an uncommon and potentially mutilating disease. Although its occurrence is relatively rare worldwide, the rates of penile cancer can be high in some developing countries (Gross \& Pfister 2004). The incidence rates of penile cancer vary enormously among different populations, but are highest in some poor countries. The disease can constitute up to $10 \%$ of malignant cancer disease in men in some African, Asian and South American countries, with incidence rates of 4.2 and 4.4 per 100,000 men in Paraguay and Uganda, respectively (Wabinga et al. 2000, Rubin et al. 2001). In Brazil, incidence rates reach 2.0 per 100,000 men, indicating that the disease prevalence is high in this country (INCA 2006). It is interesting to note that while the mean age at diagnosis of patients with penile cancer is 60 years, with an age-related incidence rising constantly to reach its highest level at 70 years, the disease may occasionally present in younger men. The substantial worldwide variation in penile cancer incidence rates is likely linked to differences in socioeconomic and religious conditions (Barnholtz-Sloan et al. 2007).

Epidemiological evidence has established that penile cancers are related to infection with human papillomavirus (HPV). Several studies have shown that an infec-

Financial support: CNPq, PROPPI/UFF

+ Corresponding author: silviacavalcanti@vm.uff.br

Received 23 March 2011

Accepted 16 August 2011 tion with mucosal high-risk (hr) HPV, mainly type 16 , is involved in the pathogenesis of a subset of penile carcinomas (Rubin et al. 2001, Heideman et al. 2007). The prevalence of penile carcinomas carrying hrHPV DNA ranges from $30-100 \%$, depending on the methods of HPV detection, population studied and histological subtype (McCance et al. 1986, Rubin et al. 2001). In a comprehensive review of the literature, Bleeker et al. (2009) showed that $45 \%$ of penile cancers are HPV-associated, with HPV 16 being the dominant viral type, found in $63 \%$ of the positive cases.

In Brazil, information regarding penile HPV infection is primarily derived from studies that examined husbands of female cervical cancer cases, cross-sectional studies of selected populations (such as individuals treated at sexually transmitted diseases clinics) and small prospective studies, which together revealed prevalence rates ranging from $30-80 \%$ (WHO/ICO 2010). Although only a few studies have been conducted, HPV infection has been detected in $75 \%$ of penile cancer cases (Scheiner et al. 2008).

In addition to HPV infection, other risk factors for penile cancer include lack of circumcision and poor penile hygiene. Smoking and phimosis have also been identified as strong risk factors, as well as other sexually transmitted agents (Bleeker et al. 2009).

Epstein-Barr virus (EBV) is among the sexually transmitted viruses that might be a cofactor in cancer development. EBV has been frequently found in the genital mucosa, urethral discharges and genital ulcers. The oncogenic potential of EBV is well known and an association between EBV and HPV has been proposed for cervical cancer. EBV also presents histological features 
resembling those of mucosal HPV, such as koilocytosis. Voog (1996) found EBV and HPV DNA in male genital lesions with a higher prevalence than in the control group, but the differences were not statistically significant. As HPV was determined as aetiology in anogenital cancers, EBV studies were put aside. Nevertheless, the cause of approximately $50 \%$ of human penile cancers is still unknown and a recent study has proposed the role of EBV as a cofactor in HPV integration and induction of malignant transformation (Szostek et al. 2009).

The aim of our study was to determine HPV prevalence rates and main genotypes present in penile cancer cases from patients treated at two cancer hospitals in state of Rio de Janeiro (RJ), Brazil. EBV prevalence rates were studied, as well as viral co-infections, in order to elucidate viral interactions that might contribute to cancer development.

\section{PATIENTS, MATERIALS AND METHODS}

Study design - This was a cross-sectional study designed to evaluate the presence of HPV infection in penile cancer cases. From all cases in RJ, 135 samples were selected as a statistically significant group for adequate analysis (confidence interval 95\%).

Samples - One hundred and thirty-five penile cancer specimens were collected at the National Cancer Institute (INCA) and at the Mario Kröeff Hospital between 2007-2010. The study was approved by the INCA Ethical Committee (CEP INCA 067/07). All subjects signed an informed consent form to participate in the study.

Two to five centimetre fragments were collected from the tumour region during surgical procedure and kept in TE solution $[10 \mathrm{mM}$ Tris hydrochloride $\mathrm{pH} 7.5$, $1 \mathrm{mM}$ ethylenediamine tetraacetic acid (EDTA)] at $-20^{\circ} \mathrm{C}$ until DNA extraction.

Histopathology - Paraffin-embedded tissues were processed at the Pathology Service from INCA and classified as follows: well differentiated squamous cell carcinoma (WDSCC), moderate differentiated SCC (MDSCC) and poorly differentiated SCC (PDSCC). A few cases were classified as in situ carcinoma and noninvasive verrucous carcinoma.

DNA extraction - Samples were incubated for $4 \mathrm{~h}$ at $56^{\circ} \mathrm{C}$ in digestion buffer $(10 \mathrm{mM}$ Tris hydrochloric acid pH 8.3, 1 mM EDTA pH 8.0, 0.5\% Tween 20, $400 \mu \mathrm{g} / \mathrm{mL}$ proteinase $\mathrm{K}$ ). The samples were subsequently extracted with phenol-chloroform-isoamyl alcohol (25:24:1). The DNA was precipitated with one-tenth volume of $0.3 \mathrm{M}$ sodium acetate and three volumes of ice-cold $100 \%$ ethanol, washed with $70 \%$ ethanol, air-dried and suspended in $50 \mu \mathrm{L}$ of sterile water.

Polymerase chain reaction (PCR) using consensus primers for the detection of HPV - MY09/11 consensus primers, which amplify 450 bp DNA sequences within the L1 region of HPV, were used to detect generic HPV DNA. Amplification was carried out in $50 \mu \mathrm{L}$ of reaction mixture $11 \times$ PCR buffer, $200 \mathrm{mM}$ deoxynucleotide triphosphates (dNTPs), $1.5 \mathrm{mM} \mathrm{MgCl} 2,50$ pmoles of each primer, 0.25 units $(\mathrm{U})$ of Taq polymerase and $5 \mu \mathrm{L}$ of DNA sample] with 35 cycles of amplification. Each cycle included a denaturation step at $94^{\circ} \mathrm{C}$ for $1 \mathrm{~min}$, an annealing step at $55^{\circ} \mathrm{C}$ for $2 \mathrm{~min}$ and a chain elongation step at $72^{\circ} \mathrm{C}$ for 2 min using a DNA Thermal Cycler (Perkin Elmer, Cetus). The beta-actin primers Acl and Ac2 (0.1 pmol each), which amplify a 330-bp region of the human DNA, were used as a sample internal control. Negative controls for background contamination were added to the DNA template. PCR products were analysed on $1.3 \%$ agarose gel with ethidium bromide staining for visualisation of DNA under ultraviolet (UV) light and their molecular weights were determined by comparison with a 100-bp DNA ladder (Silva et al. 2009).

PCR for HPV genotyping - Typing was done by PCR amplification with primers for the E6 gene DNA sequences of HPV 6, 11, 16, 18, 31, 33, 35, 45 and 58 (Silva et al. 2009). All 135 studied samples were submitted to this reaction. Amplification was carried out in $50 \mu \mathrm{L}$ of reaction mixture $(1 \mathrm{x}$ PCR buffer, $200 \mathrm{mM}$ dNTPs, 1.5 $\mathrm{mM} \mathrm{MgCl2}$, 50 pmoles of each primer, $0.25 \mathrm{U}$ of Taq polymerase and $5 \mu \mathrm{L}$ of DNA sample) with 35 cycles of amplification. Each cycle included a denaturation step at $94^{\circ} \mathrm{C}$ for $30 \mathrm{sec}$, an annealing step at $55^{\circ} \mathrm{C}$ for $30 \mathrm{sec}$ and a chain elongation step at $72^{\circ} \mathrm{C}$ for 1 min using a DNA Thermal Cycler. Negative controls for background contamination were added to the DNA template. PCR products were analysed on $1.3 \%$ agarose gel with ethidium bromide staining for visualisation of DNA under UV light and their molecular weights were determined by comparison with a 100-bp DNA ladder.

Restriction fragment length polymorphism (RFLP) analysis for HPV genotyping - HPV typing was performed by RFLP analysis following PCR amplification. The 450-bp amplicons resulting from the MY09/11 PCR were submitted to digestion by a panel of six restriction endonucleases (BamHI, DdeI, HaeIII, HinfI, PstI, RsaI) (Invitrogen, Brazil). The pattern of length polymorphism of each sample was analysed under UV light and compared with RFLP patterns for mucosal virus types, as described by Melgaço et al. (2010).

Nested PCR for the detection and typing of EBV The first PCR round was performed with $5 \mu \mathrm{L}$ of DNA sample in $50 \mu \mathrm{L}$ of reaction mixture containing $0.25 \mathrm{U}$ of Taq DNA polymerase, $1.5 \mathrm{mM} \mathrm{MgCl}, 5 \mu \mathrm{L}$ of $10 \mathrm{x}$ PCR buffer, $200 \mathrm{mM}$ dNTPs and 20 pmoles of each primer common to both EBV genotypes (E2P1: 5'-AGGGATGCCTGGACACAAGAG-3': E2P2: 5'-TGGTGCTGCTGGTGGYGGCAAT-3') for amplification of a $596 \mathrm{bp}$ fragment in the $E B N A-2$ gene. After denaturation of the template DNA at $94^{\circ} \mathrm{C}$ for $5 \mathrm{~min}$, the PCR was performed for 35 cycles using a DNA Thermal Cycler. Each cycle consisted of denaturation at $94^{\circ} \mathrm{C}$ for $30 \mathrm{sec}$, primer annealing at $60^{\circ} \mathrm{C}$ for $30 \mathrm{sec}$ and primer extension at $72^{\circ} \mathrm{C}$ for $1 \mathrm{~min}$; after all cycles were complete, a final elongation step at $72^{\circ} \mathrm{C}$ for $7 \mathrm{~min}$ was performed. The second PCR round was performed with $2 \mu \mathrm{L}$ of the products of the first PCR with different primers, namely the EBV-1 and EBV-2 type-specific inner primers: Ap1 (5'-TCTTGATAGGGATCCGCTAGGATA-3') and Ap2 (5'-ACCGTGGTTCTGGACTATCTGGATC-3') for EBV-1 and 
Bp1 (5'-CATGGTAGCCTTAGGACATA-3') and Bp2 (5'-AGACTTAGTTGATGCCCTAG-3') for EBV-2 in two sets of amplification tubes. After denaturation of the template DNA at $94^{\circ} \mathrm{C}$ for $5 \mathrm{~min}$, the PCR was performed for 25 cycles. Each cycle consisted of denaturation at $94^{\circ} \mathrm{C}$ for $30 \mathrm{sec}$, primer annealing at $60^{\circ} \mathrm{C}$ for $20 \mathrm{sec}$ and primer extension at $72^{\circ} \mathrm{C}$ for $45 \mathrm{sec}$; after all cycles were complete, a final elongation step at $72^{\circ} \mathrm{C}$ for $7 \mathrm{~min}$ was performed (Durmaz et al. 1998). Negative controls for background contamination were added to the DNA template. PCR products were analysed on $1.3 \%$ agarose gel with ethidium bromide staining for visualisation of DNA under UV light and their molecular weights were determined by comparison with a 100-bp DNA ladder.

Statistical analysis - A data bank was generated and analysed using the Epi Info 2008 statistical software package (Center for Disease Control and Prevention, Atlanta, USA). The biological data differences were compared through chi-square tests with a Mantel-Haenszel correction. The significance level of tests (p) was set at 0.05 .

\section{RESULTS}

Specimens of penile tumours from 135 patients were analysed. The mean age of the patients was 58.5 years, ranging from 21-87 years. Histological analysis classified the tumours as 126 invasive SCC, further categorised as five PDSCC (3.7\%), 81 MDSCC (60\%) and 30 WDSCC (22.2\%). Two samples were classified as in situ carcinoma $(1.5 \%)$ and seven as non-invasive verrucous carcinoma (5.1\%). Ten specimens had incomplete histological grading and were classified as SCC only.

As revealed by generic MY09/11 PCR, HPV DNA was detected in $57 \%(77 / 135)$ of the samples. PCR using specific primers showed another five HPV-positive samples that PCR MY09/11 failed to detect; among these, three samples were positive for HPV 45 and two for HPV 18 . Hence, the total prevalence rate was $60.7 \%(82 / 135)$.

Regarding HPV infection in the different histological types of tumours, PCR showed the presence of HPV DNA in 66.6\% (20/30) of WDSCC samples, 51.8\% (42/81) of MDSCC samples, $100 \%(5 / 5)$ of PDSCC samples, $100 \%(2 / 2)$ of in situ carcinoma samples and $71.4 \%(5 / 7)$ of verrucous carcinoma samples (Table I). No statistical significance was found between the histological tumour type and viral detection $(\mathrm{p}>0.05)$. When HPV prevalence was analysed in specific histological types compared to the total SCC samples evaluated, a statistically significant trend was observed for PDSCC ( $\mathrm{p}=0.051)$.

Fifteen HPV genotypes were identified by type-specific PCR and RFLP. Among these genotypes, six are recognised as hrHPV (HPV 16, 18, 31, 33, 35, 45), three as probable hr (HPV 26, 53, 73), three as low-risk (HPV $6,11,70)$ and three that remain classified as undetermined risk (HPV 28, 53, 71). From the $82 \mathrm{HPV}$-positive samples, 57 samples $(69.5 \%)$ represented hr virus types. The most prevalent type was HPV 16 (29.7\%), followed by HPV 45 (23\%). Among the other HPV types detected, we found HPV 6 in nine samples, HPV 18 in five samples and HPV 31 in four samples; HPV 11, 71, 62 and 28 were found in two samples each and HPV 33, 70, 26, 73, 53 and 35 were found in one sample each. Seven samples presented mixed infections $(9.2 \%)$ and 11 samples (12.1\%) remained untyped by both methods.

In Table I we show that HPV 16 and 45 had a higher prevalence rate in MDSCC and WDSCC samples: $69 \%$ (29/42; 16 HPV 16 and 13 HPV 45) and 30\% (6/20), respectively. HPV 6 was more commonly detected in WDSSC samples $(2 / 20 ; 10 \%)$. Mixed infections had a homogenous distribution along the histological tumour types except for in situ carcinoma, which had only one HPV type detected. Statistical analysis did not point out any correlation between viral genotypes and cancer histological subtypes $(\mathrm{p}>0.05)$.

Results for EBV detection showed its presence in $46.7 \%(63 / 135)$ of penile cancer samples. Nested PCR to determine EBV types revealed EBV-1 in $74.6 \%(50 / 63)$ of the positive samples and EBV-2 in only $25.4 \%(17 / 63)$, with a statistically significant difference $(\mathrm{p}=0.000003)$ and a relative risk of 2.94. Five samples revealed the presence of both EBV-1 and 2 DNA (7.9\%). Analysis of the prevalence of EBV in the different histological cancer types is presented in Table II. In situ carcinoma was the only histological tumour type associated with EBV infection in $100 \%$ of all samples $(2 / 2)(p=0.049)$. We also eval-

\section{TABLE I}

Prevalence of the most common human papillomavirus (HPV) genotypes according to histological grading of the lesions, determined by polymerase chain reaction and restriction fragment length polymorphism

\begin{tabular}{lcccccc}
\hline $\begin{array}{l}\text { Histological } \\
\text { subtypes }\end{array}$ & $\mathrm{n}$ & $\begin{array}{c}\text { Total HPV } \\
\mathrm{n}(\%)\end{array}$ & $\begin{array}{c}\text { HPV 16 } \\
\mathrm{n}(\%)\end{array}$ & $\begin{array}{c}\text { HPV 45 } \\
\mathrm{n}(\%)\end{array}$ & $\begin{array}{c}\text { HPV 6 } \\
\mathrm{n}(\%)\end{array}$ & $\begin{array}{c}\text { Mixed }^{a} \\
\mathrm{n}(\%)\end{array}$ \\
\hline WDSCC & 30 & $20(66.6)$ & $3(10)$ & $3(10)$ & $2(6.7)$ & $1(3.3)$ \\
MDSSC & 81 & $42(51.8)$ & $16(19.8)$ & $13(16)$ & $1(1.2)$ & $1(1.2)$ \\
PDSCC & 5 & $5(100)$ & $2(40)$ & - & $1(20)$ & $1(20)$ \\
In situ carcinoma & 2 & $2(100)$ & $1(50)$ & - & - & $1(14.3)$ \\
Verrucous carcinoma & 7 & $5(71.4)$ & $2(28.5)$ & $1(14.3)$ & $1(14.3)$ & 1 \\
\hline
\end{tabular}

a: HPV 6, 45 [well differentiated squamous cell carcinoma (WDSCC)]; HPV 16/45 verrucous carcinoma; HPV 6/31 [moderate differentiated SCC (MDSCC), poorly differentiated SCC (PDSCC)]; HPV 6, 11, 45 (no SCC subtype). 
uated the possible correlation between EBV types and the histological grade of the lesions, but no correlation was found ( $p>0.05)$, because EBV-1 was detected at similar rates in samples of WDSCC (33.6\%), MDSCC (35.8\%), PDSCC (40\%) and verrucous carcinoma (28.5\%). EBV was detected in $100 \%$ (2/2) of in situ carcinoma samples, but due to the small number of samples, the power of the statistical test is not strong.

Nested PCR to detect EBV DNA showed that out of the 135 penile carcinoma samples, $36(26.7 \%)$ were co-infected with HPV and EBV, 46 (34.1\%) were exclusively infected by HPV, $27(20 \%)$ contained only EBV DNA and 26 (19.2\%) were negative for the DNA of both viruses. Nearly $81 \%(109 / 135)$ of the samples contained at least one type of viral DNA.

Statistical analysis did not show correlation between co-infection with HPV and EBV and specific histological types, except for in situ carcinoma, which had $100 \%(2 / 2)$ of the studied samples co-infected by EBV-1 and HPV.

Finally, no statistically significant difference was detected when analysing viral infection in different age groups (men younger than 60 years; men older than 60 years) for both HPV $(p=0.66)$ and EBV $(p=0.46)$.

\section{DISCUSSION}

Penile cancers are thought to arise from precursor lesions and can be subdivided into HPV-positive and HPV-negative cases, similar to vulvar and head and neck carcinomas (Cubilla et al. 2000, Bezerra et al. 2001). Studies from Brazil have described HPV prevalence rates ranging from $30-75 \%$ (WHO/ICO 2010).

In our study, we found a total HPV prevalence of $60.7 \%$. These results are in agreement with those from Scheiner et al. (2008) who used the same methodologies and found an HPV prevalence of approximately $75 \%$. Other authors have described lower rates $(50 \%)$ of penile cancer in northeastern Brazil, but the method used (Southern blot) to detect HPV has a lower sensitivity (McCance et al. 1986). Previous studies investigated HPV in histologically distinct carcinomas (WHO/ICO 2010), but no conclusive association was observed. When we classified SCC cases into different histological subtypes, we observed that the PDSCC lesions were $100 \%$ positive (5/5) for HPV DNA. Gregoire et al. (1995) had already found a statistical association relating HPV infection and these lesions. In our study, statistical analysis showed a trend $(\mathrm{p}=0.051)$, but due to our small number of samples no definite conclusions were drawn. MDSCC showed HPV prevalence rates of $51.8 \%(42 / 81)$. It is important to note that 81 out of the 135 samples studied were MDSCC, the most common subtype studied. In WDSCC samples, the HPV prevalence rate was $66.6 \%(20 / 30)$. HPV had a high prevalence rate of $71.4 \%(5 / 7)$ in non-invasive verrucous carcinoma and $100 \%(2 / 2)$ in in situ carcinoma (Table I), but both had low sample numbers.

HPV typing revealed 15 different genotypes. The most prevalent type was HPV 16 (29.7\%), confirming its worldwide recognition as the most common HPV type associated with genital cancer (WHO/ICO 2010). Oncogenic HPV 45 also had a high prevalence in the samples tested $(23.1 \%)$, which represents a new finding because previous studies showed HPV 18 as the second most common hrHPV, with prevalence rates ranging from $10-15 \%$ (McCance et al. 1986, Bezerra et al. 2001). In our study, only $5.5 \%$ of the samples contained HPV 18 . It is important to emphasise that other studies recently published (Sanjosé et al. 2010) have already detected a decrease in HPV 18 circulation simultaneous with increasing rates in HPV 45 detection, which might be due to a biological replacement in ecological niches occurring either naturally or in response to selective pressure resulting from vaccination programs. In Brazil, HPV vaccines have been licensed since 2006 and have not been extensively used due to the high cost; hence, the possible effects on the epidemiology of HPV infection are not yet known. It is interesting to note that HPV 45 belongs to the same phylogenetic clade as HPV 18, displaying genetic similarities that lead authors to place HPV 45 as a recent evolutionary variant derived from HPV 18 (Chen et al. 2009). Several studies have defined HPV 18 as the most oncogenic and aggressive HPV type related to human cancer, showing a poor prognosis in terms of response to treatment, as well as overall survival. Due to the similar genetic profile, we suggest

\section{TABLE II}

Prevalence of Epstein-Barr virus (EBV) types according to histological classification of the lesions, determined by polymerase chain reaction

\begin{tabular}{|c|c|c|c|c|c|}
\hline $\begin{array}{l}\text { Histological } \\
\text { types }\end{array}$ & $\mathrm{n}$ & $\begin{array}{l}\text { EBV } \\
\mathrm{n}(\%)\end{array}$ & $\begin{array}{c}\text { EBV-1 } \\
\text { n (\%) }\end{array}$ & $\begin{array}{c}\text { EBV-2 } \\
\text { n (\%) }\end{array}$ & $\begin{array}{c}\mathrm{EBV}-1 / \mathrm{EBV}-2 \\
\mathrm{n}(\%)\end{array}$ \\
\hline WDSCC & 30 & $14(46.6)$ & $10(33.3)$ & $3(10)$ & $1(3.3)$ \\
\hline MDSCC & 81 & 38 (46.9) & $26(32.1)$ & $8(9.8)$ & $4(4.9)$ \\
\hline PDSCC & 5 & $3(60)$ & $2(40)$ & $1(20)$ & - \\
\hline In situ carcinoma & 2 & $2(100)$ & $2(100)$ & - & - \\
\hline Verrucous carcinoma & 7 & $2(28.5)$ & $2(28.5)$ & - & - \\
\hline TOTAL & 125 & $59^{a}(47.2)$ & $41^{a}(32.8)$ & $12(9.6)$ & $5(4)$ \\
\hline
\end{tabular}

$a$ : four samples remained without histopathological classification, totalizing 63 EBV positive samples; MDSCC: moderate differentiated squamous cell carcinoma; PDSCC: poorly differentiated SCC; WDSCC: well differentiated SCC. 
that HPV 45 might also be associated with a poor prognosis, meriting further follow-up studies. Sanjosé et al. (2010) showed that HPV 45 is rarely seen in precursor lesions, which might reinforce the idea of an early poor outcome, even in screened women. The relevance of this finding also suggests the close management of future prophylactic vaccines, because poor cross-protection $(7.6 \%)$ was observed with use of the quadrivalent HPV vaccine (Brown et al. 2009).

Our results also placed HPV 6 as the third most prevalent HPV type in penile cancer $(9.9 \%)$. Association of a small subset of penile cancers with low-risk HPV types has been previously suggested (Senba et al. 2006). However, whether mucosal low-risk or cutaneous HPV types are aetiologically involved in the pathogenesis of penile cancer is not yet clear (Heideman et al. 2007). In a meta-analysis involving 27 studies worldwide (WHO/ ICO 2010) HPV 6 was the second most prevalent type, following HPV 16, with an overall prevalence of nearly $7 \%$, in agreement with our findings.

We also detected the occurrence of mixed HPV infections in approximately $9 \%$ of the samples, some of which contained both low and hr types (44.4\%), in agreement with WHO/ICO (2010) meta-analysis (40\%) (Table I). We observed the occurrence of HPV 11 exclusively in these mixed infections, suggesting a synergistic or opportunistic role for this viral genotype in carcinogenesis. Previously, Hippeläinen et al. (1993) have described combined lesions presenting the histological features of benign condylomas and severe neoplasias associated with multiple HPV types, which might explain the detection of a low-risk HPV type in a malignant lesion.

It is important to note that even our prevalence rates can be underestimated because of losses in molecular detection due to DNA degradation, primer choice and viral DNA integration in the lesions, the last of which is a necessary step towards malignant transformation. The disruption of the E1/E2 genes would also result in loss of parts of the HPV genome, including the $L 1$ gene, which is the target of MY09/11 primers. In our study we detected five HPV infections (6\%, 3 HPV 45 and 2 HPV 18) in MY negative samples. Depuydt et al. (2007) described similar findings and pointed out a loss of $10 \%$ of samples in MY09/11 PCR when compared with type-specific PCR. These authors also demonstrated a similar loss of nearly $20 \%$ associated with the HPV 45 genotype; in our study we had a loss of $14.2 \%$. In addition, after using PCR and RFLP, $12.1 \%$ of the samples remained untyped, mostly due to complex patterns generated by the polymorphism analysis (Melgaço et al. 2010).

In evaluating HPV infection in different histological subtypes, we did not find statistical significance, which is consistent with Miralles-Guri (2009), who described HPV 16 as the most prevalent virus in all histological subtypes (Table I).

Despite the similarities between penile and vulvar cancer, including the presence of HPV (mainly HPV 16 ) and the precursor lesions, the clear bimodal age distribution that is found for vulvar cancer has not been seen in our penile cancer cases, corroborating data from Lont et al. (2006).
Although the aetiology of penile cancers is not yet fully understood, penile carcinoma is recognised as a multi-step process showing a polyclonal profile. A proportion of penile carcinoma is attributable to hrHPV infection, while in the remaining penile cancers molecular mechanisms independent of HPV are likely to be the more common underlying events (Bleeker et al. 2009). Hence, several studies have been conducted in order to identify possible additional risk factors. The observation of other sexually transmitted agents as possible factors involved in carcinogenesis has led several authors to look for the presence of EBV, a recognised oncogenic virus already associated with several human cancers (Young \& Murray 2003).

In this study, we detected EBV DNA in $46.7 \%$ of the samples. The EBV-1 sub-type, accepted as the most pathogenic genotype, was the most prevalent, detected in $74.6 \%$ of the positive samples, in comparison with EBV-2 $(25.4 \%)(p=0.0003)$. These results are consistent with those from Gratama and Ernberg (1995). When we evaluated the distribution of EBV types among the different penile cancer subtypes, there was no statistical significance, with EBV-1 appearing equally distributed in all lesions (Table II).

Our findings on the interaction of HPV and EBV in penile cancer showed that $26.7 \%$ of the studied samples contained both viruses, while $34.1 \%$ had only HPV DNA, $19.2 \%$ were negative for both HPV and EBV DNA and $20 \%$ were exclusively positive for EBV DNA. These results suggest a role for both viruses, singly or synergistically, in penile cancer development. Szostek et al. (2009) have already proposed a synergistic interaction between EBV and HPV in cervical neoplasia, demonstrating that EBV was associated with seven times the risk of HPV 16 integration. In fact, EBV infection has been already implicated in cellular growth stimulation, inhibition of apoptosis and immune escape through mimicking interleukin-10, a cytokine that acts in local immune suppression and would thus facilitate HPV infection in epithelial cells (Susuki et al. 1995).

Regarding prophylactic measures available worldwide, we have estimated that using the quadrivalent vaccine, that contains HPV 6, 11, 16 and 18 and supposing an efficacy of $90 \%$ described by Harper et al. (2006), we could achieve a protection rate of $27 \%$, which should be analysed in terms of the associated costs and benefits.

In conclusion, we have described a change in the distribution of circulating HPV genotypes that may possibly affect the recently proposed prophylactic measures. In addition, we believe that further studies are necessary to fully understand the aetiology of penile cancer and the possible role of microbiological interactions in this disease, in order to contribute to cancer prevention and control.

\section{REFERENCES}

Barnholtz-Sloan JS, Maldonado JL, Pow-sang J, Giuliano AR 2007. Incidence trends in primary malignant penile cancer. Urol Oncol 25: 361-367.

Bezerra AL, Lopes A, Santiago GH, Ribeiro KC, Latorre MR, Villa LL 2001. Human papillomavirus as a prognostic factor in carcinoma of the penis: analysis of 82 patients treated with amputation and bilateral lymphadenectomy. Cancer 91: 2315-23211. 
Bleeker MCG, Heideman DAM, Snijders PJF, Horenblas S, Dillner J, Meijer CJLM 2009. Penile cancer: epidemiology, pathogenesis and prevention World J Urol 27: 141-150.

Brown DR, Kjaer Sk, Sigurdsson K, Iversen O, Hernandez-Avila M 2009. The impact of quadrivalent human papillomavirus (HPV types $6,11,16$ and 18) L1 virus-like particle vaccine on infection and disease due to oncogenic non-vaccine HPV types in generally HPV-naïve women aged 16-26 years. J Infect Dis 199: 926-935.

Chen Z, DeSalle R, Schiffman M, Herrero R, Burk RD 2009. Evolutionary dynamics of variant genomes of human papillomavirus types 18, 45 and 97. J Virol 8: 1443-1455.

Cubilla AL, Velazques EF, Reuter VE, Oliva E, Mihm MC Jr, Young RH 2000. Warty (condylomatous) squamous cell carcinoma of the penis: a report of 11 cases and proposed classification of "verruciform" penile tumours. Am J Surg Pathol 24: 505-512.

Depuydt CE, Boulet GAV, Horvath CAJ, Benoy IH, Vereecken AJ, Bogers JJ 2007. Comparison of MY09/11 consensus PCR and type-specific PCRs in the detection of oncogenic HPV types. J Cell Mol Med 11: 881-891.

Durmaz R, Aydin A, Köroglu M, Aker H, Ozercan IH, Atik E, Arici S 1998. Detection and genotyping of Epstein-Barr virus by polymerase chain reaction in tissue obtained from cases with Hodgkin's disease in Turkey. Acta Virol 42: 375-381.

Gratama JW, Ernberg I 1995. Molecular epidemiology of EpsteinBarr virus infection. Adv Cancer Res 67: 197-255.

Gregoire L, Cubilla AL, Reuter VE 1995. Preferential association of human papillomavirus with high-grade histologic variants of penile-invasive squamous cell carcinoma. J Natl Cancer Inst 87: $1705-1709$.

Gross G, Pifster H 2004. Role of human papillomavirus in penile cancer, penile intraepithelial squamous cell neoplasias and in genital warts. Med Microbiol Immunol (Berl) 193: 35-44.

Harper DM, Franco EL, Wheeler CM, Moscicki AB, Romanowski B 2006. Sustained efficacy up to 4.5 years of a bivalent L1 virus-like particle vaccine against human papillomavirus types 16 and 18: follow-up from a randomised control trial. Lancet 367: 1247-1255.

Heideman DA, Waterboer T, Pawlita M, Delis-van DP, Nindl I, Leijte JA, Bonfrer JM, Horenblas S, Meijer CJ, Snijders PJ 2007. Human papillomavirus-16. Is the predominant type etiologically involved in penile squamous cell carcinoma? J Clin Oncol 25: 4550-4556.

Hippeläinen M, Syrjanen S, Koskela H, Pulkkinen J 1993. Prevalence and risk factors of genital human papillomavirus (HPV) infections in healthy males: a study on Finnish conscripts. Sex Transm Dis 20: 321-328.

INCA - Instituto Nacional de Câncer 2006. Estimativa da incidência e mortalidade por câncer no Brasil. Available from: inca.org.br.

Lont AP, Kroon BK, Horenblas S, Gallee MP, Berkhof J, Meijer CJ, Snijders PJ 2006. Presence of high-risk human papillomavirus DNA in penile carcinoma predicts favourable outcome in survival. Int J Cancer 119: 1078-1081
McCance DJ, Kalache A, Ashdown K, Andrade L, Menezes F, Smith P, Doll R 1986. Human papillomavirus types 16 and 18 in carcinomas of the penis from Brazil. Int J Cancer 37: 55-59.

Melgaço FG, Rosa MLG, Augusto EF, Haimuri JGS, Jacintho C, Santos LS, Cavalcanti SMB, Oliveira LHS 2010. Human papillomavirus genotypes distribution in cervical samples from women living with human immunodeficiency virus. Arch Gynecol Obstet 283: 809-817.

Miralles-Guri C, Bruni L, Cubilla AL, Castellsague X, Bosch FX, Sanjose S 2009. Human papillomavirus prevalence and type distribution in penile carcinoma. $J$ Clin Pathol 62: 870-878.

Rubin MA, Kleter B, Zhou M, Ayala G, Cubilla AL, Quint WG, Pirog EC 2001. Detection and typing of human papillomavirus DNA in penile carcinoma: evidence for multiple independent pathways of penile carcinogenesis. Am J Pathol 159: 1211-1218.

Sanjosé S, Quint WGV, Alemany L, Geraets DT, Klaustermeier JE 2010. Human papillomavirus genotype attribution in invasive cervical cancer: a retrospective cross-sectional worldwide study. Lancet Oncol 11: 1048-1056.

Scheiner MA, Campos MM, Ornellas AA 2008. Human papillomavirus and penile cancers in Rio de Janeiro Brazil: HPV typing and clinical features. Int Braz J Urol 34: 467-476.

Senba M, Kumatori A, Fujita S, Jutavijittum P, Yousukh A, Moriuchi T, Nakamura T, Toriyama K 2006. The prevalence of human papillomavirus genotypes in penile cancers from northern Thailand. J Med Virol 78: 1341-1346.

Silva KC, Rosa MLG, Moyses N, Afonso LA, Oliveira LHS, Cavalcanti SMB 2009. Risk factors associated with human papillomavirus infection in two populations from Rio de Janeiro, Brazil. Mem Inst Oswaldo Cruz 104: 885-891.

Suzuki T, Tahara H, Narula S, Moore KW, Robbins PD, Lotze MT 1995. Viral interleukin 10 (IL-10), the human herpes virus 4 cellular IL-10 homologue, induces local anergy to allogeneic and syngeneic tumors. $J$ Exp Med 182: 477-486.

Szostek S, Zawilinska B, Kopec J, Kosz-Vnenchak M 2009. Herpesviruses as possible cofactors in HPV-16-related oncogenesis. Acta Biochim Polon 56: 337-342.

Voog E 1996. Genital viral infections. Studies on human papillomavirus and Epstein-Barr virus. Acta Derm Venereol (Stockh) 198 (Suppl.): 1-55.

Wabinga HR, Parkin DM, Wabwire-Mangen F, Nambooze S 2000. Trends in cancer incidence in Kyadondo County, Uganda, 19601997. Br J Cancer 82: 1585-1592.

WHO/ICO - World Health Organization/Institut Català d'Oncologia 2010. Information Centre on HPV and Cervical Cancer. Human papillomavirus and related cancers in Brazil. Summary report. Available from: who.int/hpvcentre.

Young LS, Murray PG 2003. Epstein-Barr virus and oncogenesis: from latent genes to tumors. Oncogene 22: 5108-5121. 